\title{
Size-selected black carbon mass distributions and mixing state in polluted and clean environments of northern India
}

\section{Tomi Raatikainen et al.}

Correspondence to: Tomi Raatikainen (tomi.raatikainen@fmi.fi)

The copyright of individual parts of the supplement might differ from the CC-BY 3.0 licence. 


\section{Instrument setup}

The both Gual Pahari and Mukteshwar measurements we conducted using a Differential Mobility Particle Sizer (DMPS) coupled with a SP2 (Fig. S1). The DMPS is composed of a Differential Mobility Analyzer (DMA; medium HAUKE-type, with a bipolar radioactive (Am) neutralizer) and a Condensation Particle Counter (CPC; TSI model 3010, TSI Inc. USA). A polydisperse ambient aerosol population is dried (first drier (using silica-gel, Sigma Aldrich) was in main inlet line outside, second stage was 1 meter-long nafion drier (Perma Pure) inside the building, third drier (silica-gel, Sigma Aldrich) was in closed DMA sheath flow loop) and the charge distribution is neutralized before entering the DMA where a narrow particle size range is selected based on a voltage control (VDC) while keeping the constant flow rates (both sheath and aerosol sample: $Q_{a}$ ). The size-selected aerosol is then lead to the CPC, which measured the total number concentration of particles $\left(N_{\text {total }}\right)$. The SP2 was connected in parallel to the CPC where the SP2 measures the number concentrations of all particles $\left(N_{\text {total }}\right)$ and also those containing refractory material $\left(N_{r B C}\right)$, which is assumed to be refractory black carbon $(\mathrm{rBC})$. In addition, the SP2 measures particle sizes and the mass of refractory material $\left(m_{r B C}\right)$ in each particle. Particle size measured by the SP2 is used mainly as a diagnostic parameter; for spherical particles it should be the same as the mobility size selected by the DMA, which is used in the calculations. $\mathrm{rBC}$ core volume equivalent diameters (assuming a compact spherical rBC "core" with $1800 \mathrm{~kg}$ $\mathrm{m}^{-3}$ density) were calculated from the measured $\mathrm{rBC}$ mass.

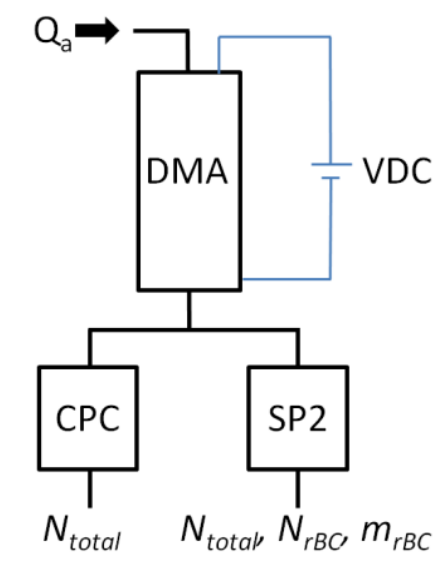

Figure S1: Schematics of the measurement setup.

The DMA voltages are changed stepwise through selected voltage range. Here 30 voltage settings were selected so that logarithmically spaced particle size bins ranged from about 20 to $650 \mathrm{~nm}$ (there were small fluctuations due to instrument temperature and pressure changes). The time step was initially set to $30 \mathrm{~s}$, but it was later increased to $60 \mathrm{~s}$ to improve the SP2 counting statistics. As a result, the full scan with $60 \mathrm{~s}$ time step took 32 minutes.

The CPC and SP2 data were aligned visually. The CPC data is automatically saved as an average concentration for each time step, but this was done manually for the SP2 data where the relevant parameters are number concentrations for all particles and those containing $\mathrm{rBC}$ (used to calculate the number fraction of particles containing $\mathrm{rBC}$ ), and $\mathrm{rBC}$ core size distributions which are here represented by suitable distribution parameters. These were calculated using the standard instrument calibration and data analysis methods (see below). The first measurements showed that the rBC core size distributions are not always narrow and unimodal, which means that the commonly used number mean rBC core diameter is smaller than the corresponding mass mean diameter. For consistency with the further mass calculations, both mass and number mean diameters were saved. 


\subsection{SP2 calibration}

The maximum incandescence and scattering signals are proportional to the refractory particle mass and the total particle size, respectively, and these dependencies are parameterized using suitable calibration reference materials. Our regular incandescence calibrations are based on size-selected Aquadag (Acheson Inc., USA) particles which masses are calculated using the density parameterization from Gysel et al. (2011). Several studies have shown that fullerene soot is the best representative of ambient $r B C$ and its incandescence signal is about $75 \%$ of that of Aquadag with the same particle mass (Moteki and Kondo, 2010; Kondo et al., 2011; Gysel et al., 2011; Baumgardner et al., 2012; Laborde et al., 2012). Therefore, Aquadag incandescence amplitudes were multiplied by a factor of 0.75 to make it representative of the fullerene soot and ambient $r B C$. This fullerene soot-equivalent calibration gives ambient $r B C$ particle mass as a function of the measured maximum incandescence signal. $r B C$ core volume equivalent diameters (briefly: $\mathrm{rBC}$ core diameter) are then calculated by assuming a compact spherical "core" with $1800 \mathrm{~kg} \mathrm{~m}^{-3}$ density. The sizing limits for the refractory material are 0.3-380 fg for $\mathrm{rBC}$ mass and $70-740 \mathrm{~nm}$ for the $\mathrm{rBC}$ core diameter.

Because particle sizes are accurately selected by the DMA especially for rBC-containing particles, scattering sizes measured by the SP2 are mainly used for diagnostic purposes. Our regular scattering size calibrations are based on size-selected ammonium sulfate, but here we can also use size-selected ambient particles. The instrument was calibrated using ammonium sulfate before shipping to India (December 13, 2013), but not during the campaign. Scattering amplitudes from the ammonium sulfate calibration and Mukteshwar observations (February 9, 2014) are almost identical with only $3 \%$ difference in particle size. Such a small difference can be easily caused by the difference in optical properties of ammonium sulfate and ambient particles or minor changes in the instrument performance. However, significant reduction in scattering signal (equivalent to $17 \%$ increase in particle size) is observed after the instrument was moved to Gual Pahari (data from April 11, 2014). This is most likely caused by decreased laser beam intensity (Laborde et al., 2012). In order to remove this constant sizing bias, Gual Pahari scattering calibration is based on field measurements (data from April 11, 2014). More details about the laser power is given in later in Sect. 3.4.

\section{Data analysis}

Just as in a typical DMPS data analysis, ambient size distributions need to be calculated from the raw observations of particle number versus voltage using an inversion code. This inversion depends mainly on particle charging efficiencies and the DMA transfer function. For the DMPS system we have used a standard pseudo-inverse method (see the FMI DMPS inversion description in Wiedensohler et al., 2012), but this method cannot be directly applied to the SP2 data. The main reason is that the SP2 cannot detect small particles (minimum rBC size is about $70 \mathrm{~nm}$ and that for scattering particles is roughly $180 \mathrm{~nm}$ ), which means that multiply charged particles dominate these size bins. To avoid problems with the data inversion, SP2 size distributions $\left(\mathrm{dN}_{\mathrm{SP} 2} / \mathrm{dlog}_{\mathrm{p}}\right)$ are calculated by multiplying the raw particle number concentrations $\left(N_{S P 2}\right)$ by the ratio of the inverted DMPS number size distribution $\left(d N_{D M P S} / d \log D_{p}\right)$ to the original particle concentrations from the CPC $\left(N_{C P C}\right): d N_{S P 2} / d l o g D_{p}=N_{S P 2} \cdot\left(d N_{D M P S} / d \log D_{p}\right) / N_{C P C}$. In order to reduce noise from the inversion and to make SP2 results less dependent on the CPC data, we have used the mode of the correction factor $\left(\left(\mathrm{dN}_{\mathrm{DMPS}} / \mathrm{d} \log \mathrm{D}_{\mathrm{p}}\right) / \mathrm{N}_{\mathrm{CPC}}\right)$, which means constant correction for each DMA size. This method is essentially the same as taking a typical DMPS scan and calculating the inversion from that. Figure S2 shows an example of the SP2 inversion method. The red markers are the individual time and size dependent values of $\left(\mathrm{dN}_{\mathrm{DMPS}} / \mathrm{dlog} \mathrm{D}_{\mathrm{p}}\right) / \mathrm{N}_{\mathrm{CPC}}$ and blue lines and markers represent the mode, which is the size dependent correction factor for the SP2 concentrations (here number concentrations of particles with and 
without $r B C, r B C$ mass concentrations, and $r B C$ core number size distributions for the $360 \mathrm{~nm}$ mobility size bin). Parameters calculated for each DMA size like the $\mathrm{rBC}$ core diameter, scattering particle size and number fraction of $\mathrm{rBC}$-containing particles are independent of particle concentrations, so inversion is not needed. Multiply charged particles have a small effect on rBC core diameters (see Fig. S14), but the exact quantification of their contribution or a correction would have required accurate identification of those particles, which is not possible.

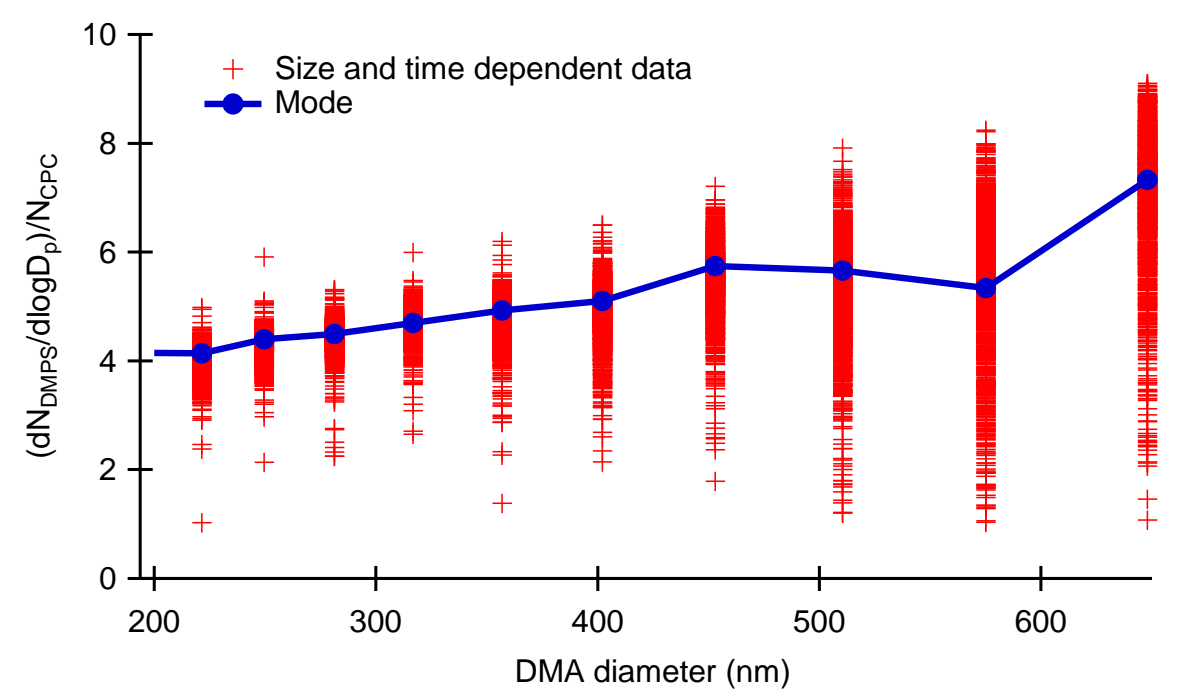

Figure S2: Size and time dependent ratios of the DMPS number size distribution ( $\mathrm{dN}_{\mathrm{DMPS}} / \mathrm{dlog}_{\mathrm{p}}$ ) to the CPC concentration $\left(N_{C P C}\right)$ from Mukteshwar measurements. The blue line and the markers (mode for each DMA diameter) show the size dependent inversion for calculating concentration from SP2 data.

\section{Consistency tests}

Since this is a new method, tests were made to confirm the validity of the results. First of all, CPC and SP2 total (all particles including those that saturate the detectors) number concentrations (used without inversion) should be equal for all DMA sizes larger than about $200 \mathrm{~nm}$, which is larger than the SP2 detection limit for scattering particles. Secondly, the DMA-selected and non-rBC particle mean diameters should be almost identical. Any fluctuation in concentration or size could mean fluctuations in SP2 performance; the DMA and CPC could have problems too, but these are generally highly stable instruments. After that, the total $\mathrm{rBC}$ mass concentrations are compared with equivalent black carbon (eBC) measured by a 7-wavelength Aethalometer in Mukteshwar. Finally, we diagnose SP2 laser power changes.

\subsection{Number concentrations}

Figure S3 shows the ratio of CPC and SP2 total number concentrations as a function of DMA size. The DMA size was limited to $200-420 \mathrm{~nm}$ size range, because scattering particle detection limit is close to $200 \mathrm{~nm}$ and low particle counts increase noise at sizes larger than $450 \mathrm{~nm}$. Although the number concentrations are correlated, there seems to be a constant bias between CPC readings and total concentrations from the SP2. The CPC readings are consistently about $82 \%$ of those of the SP2 at both sites. There are reasons that could cause such differences, but the typical explanations were ruled out (instruments were working correctly, concentrations were low enough to avoid coincidence counting errors and flow rates were calibrated for both instruments). Further tests with other CPC and SP2 showed the SP2 used in these India measurements 
is always showing larger number concentrations (the reason for this is currently unknown). Therefore, all SP2 mass and number concentration values are here multiplied by a factor of 0.82 . With this correction CPC and SP2 results become practically identical.

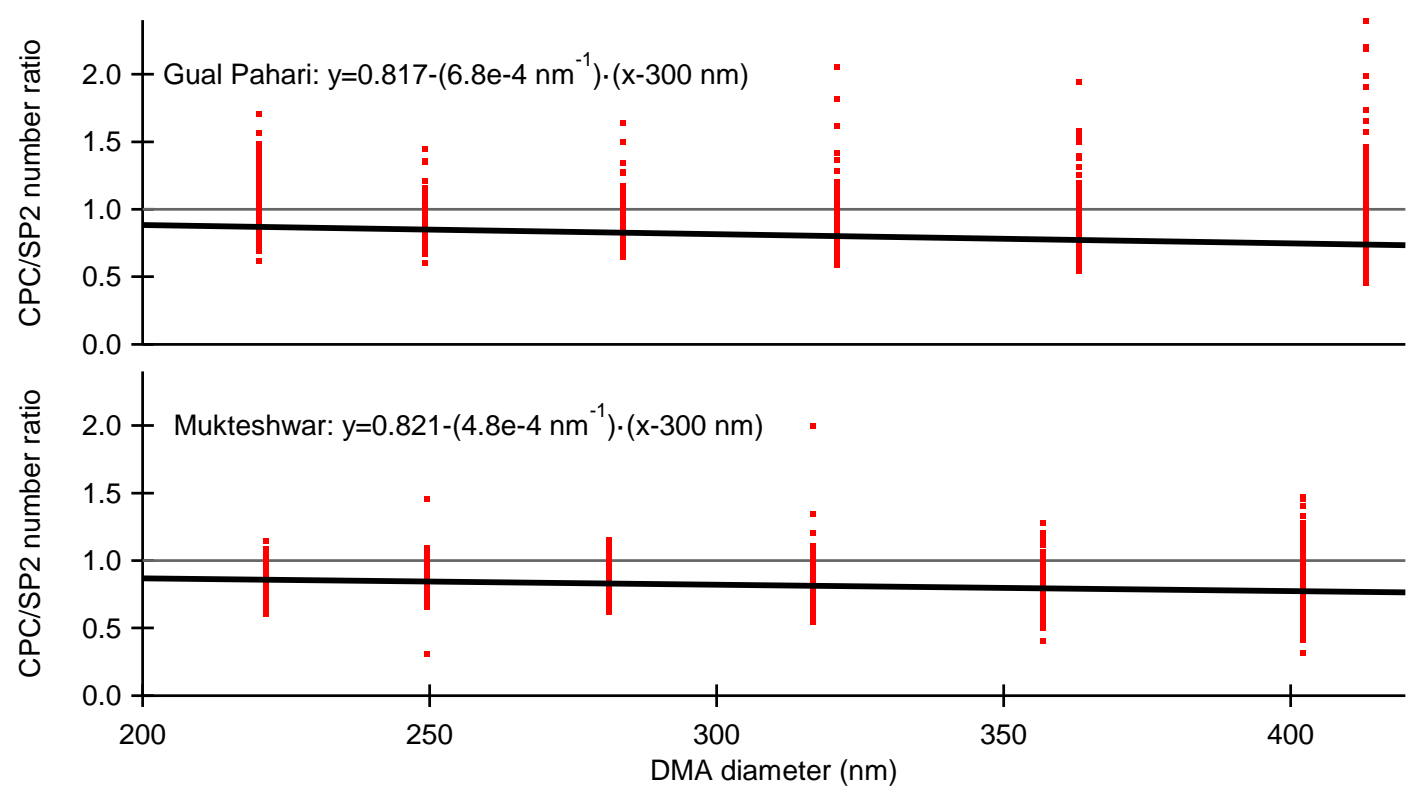

Figure S3: The CPC to total number concentration ratios as a function of DMA size for both Gual Pahari and Mukteshwar. Also shown are the linear fits to the data. The highest number ratios (about 4 for Gual Pahari) are not shown.

The figure above shows that there is some variability in the ratios, but a closer look shows that much of this variability is actually time-dependent. Furthermore, these time-dependent variations correlate with the SP2 chamber temperature. Figure $\mathrm{S} 4$ shows the number ratio for about $285 \mathrm{~nm}$ DMA diameter as a function of chamber temperature from both measurements campaigns. SP2 chamber temperature depends strongly on the temperature of the air-conditioned measurement building, but less on the ambient temperature. This indicates that the difference in particle number concentration is most likely caused by the SP2. Although temperature dependent bias correction could be applied to SP2 concentrations, a constant correction is considered to be more robust. The remaining temperature dependent bias introduces some additional noise to the mass and number concentrations, but there is no systematic error since SP2 temperature variations are not following a frequent cycle. Specifically, if the SP2 temperature would have been following the ambient temperature, the observed diurnal cycles would have been affected. 


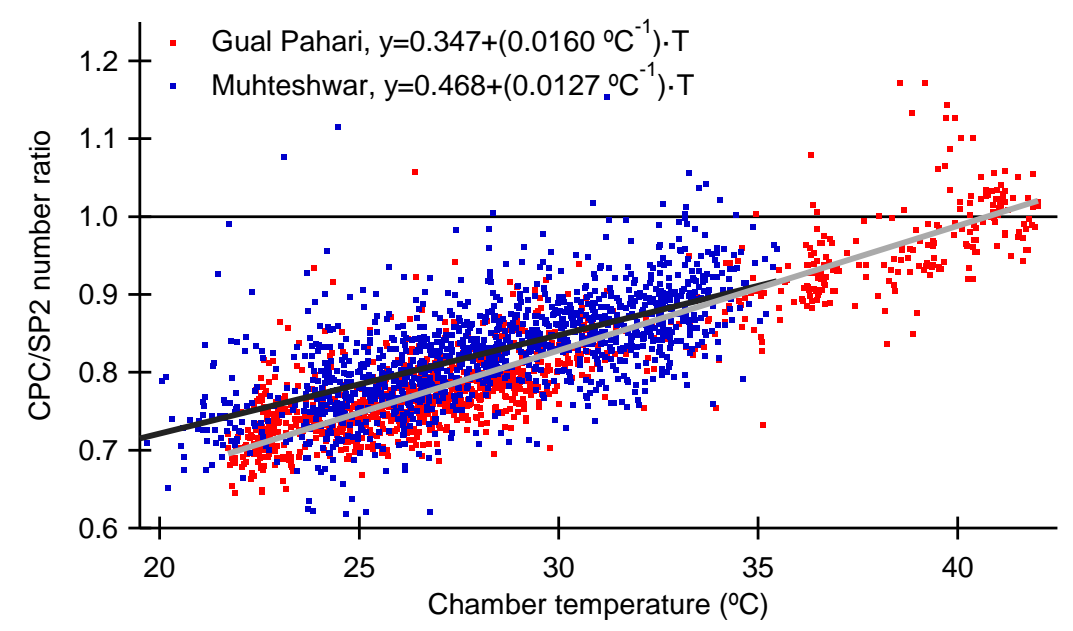

Figure S4: CPC to SP2 total number concentration ratios for $285 \mathrm{~nm}$ DMA size for both Gual Pahari and Mukteshwar. Also shown are the linear fits to the data. Clear outliers are not shown.

\subsection{Particle sizes}

Figure S5 shows the ratio of DMA selected size to those measured by the SP2 as a function of DMA size. The SP2 derived particle sizes are geometric mean diameters of the observed non-rBC particle distributions (determined by fitting a log-normal size distribution to the observed size distributions). Because scattering calibration is based on ambient particles, the average sizing bias is only about $1 \%$.

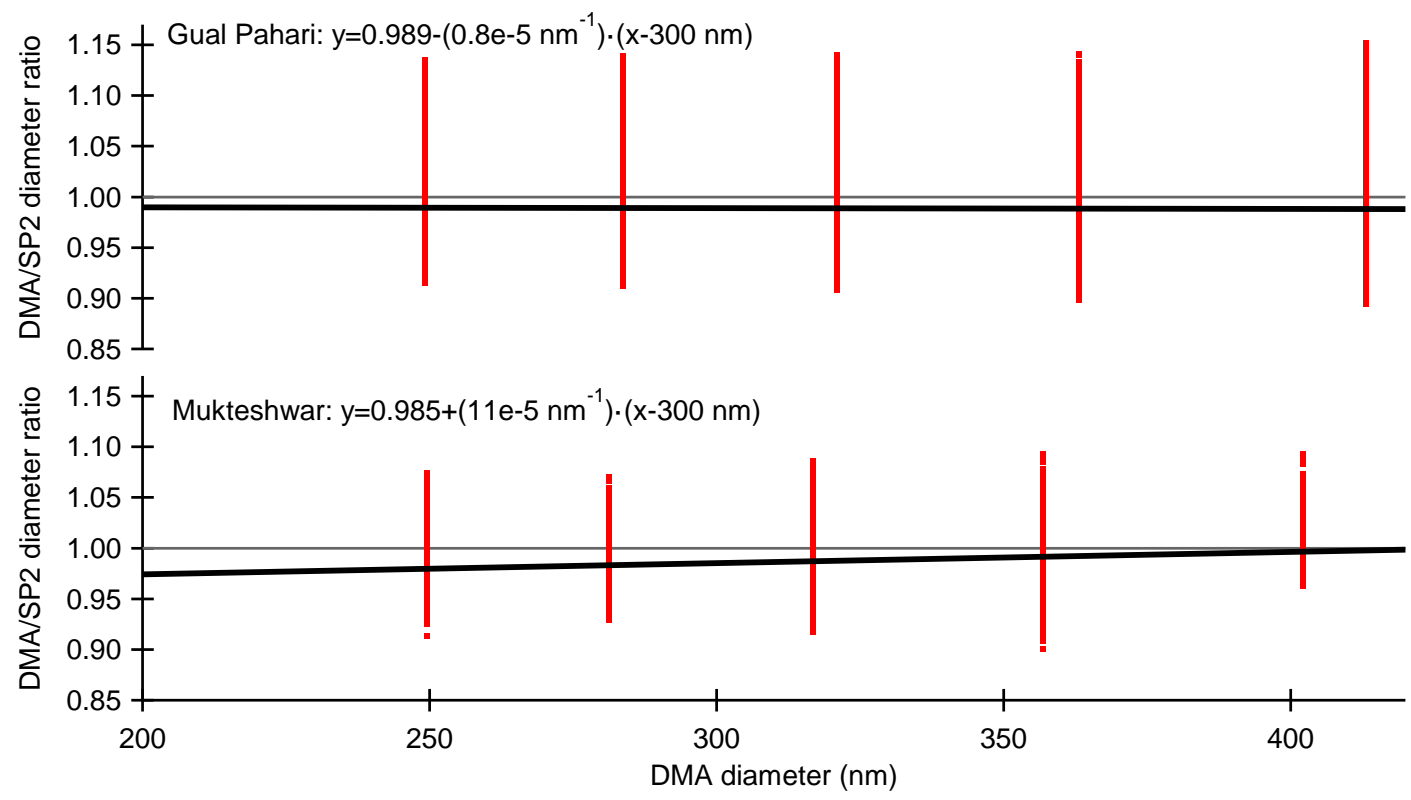

Figure S5: The DMA to scattering diameter ratios as a function of DMA size for both Gual Pahari and Mukteshwar. Also shown are the linear fits to the data.

Although the average sizing bias is negligible (about $1 \%$ ) and the bias is independent of particle size (slope in the order of $10^{-5} \mathrm{~nm}^{-1}$ ), there is some variability in the calculated scattering sizes (about $\pm 10 \%$ difference from the DMA-selected size). Again, it seems that the variability in scattering size is related to the variability of the SP2 chamber temperature (Fig. S6), but the dependency is weaker than in the case of concentrations (Fig. S4). In general, this about $10 \%$ sizing uncertainty is within the typically reported sizing uncertainty limits (e.g. Laborde et al., 2012). 


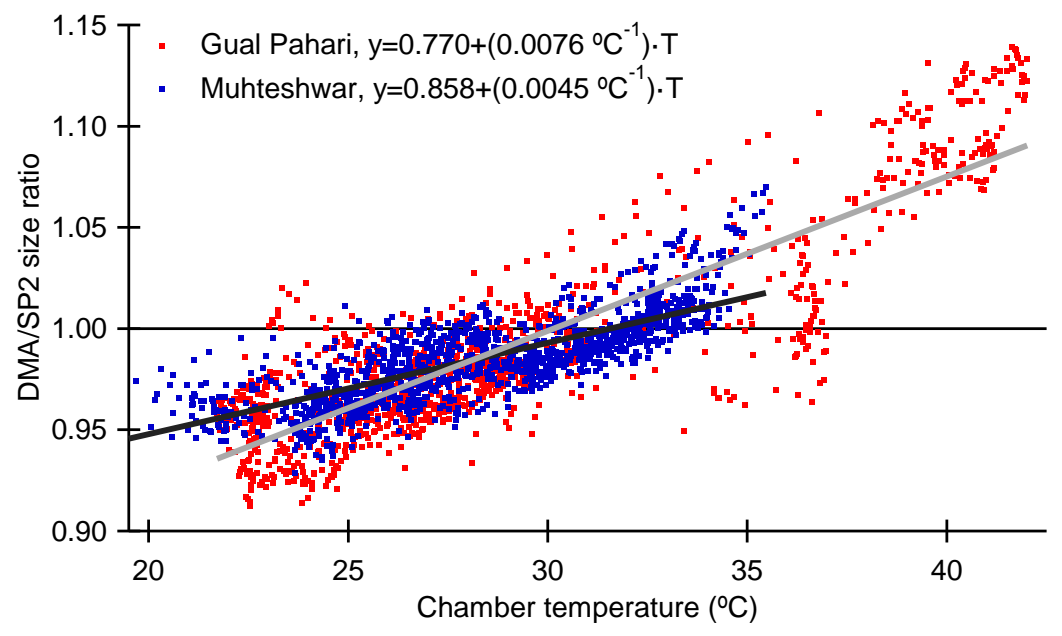

Figure S6: DMA to scattering diameter ratios for $285 \mathrm{~nm}$ DMA size for both Gual Pahari and Mukteshwar.

Also shown are the linear fits to the data. Clear outliers are not shown.

\subsection{Refractory and equivalent Black Carbon}

The Aethalometer collects particles to a filter and measures the change in light attenuation due to the accumulated absorbing aerosol mass (Hansen et al., 1984). The mass concentration of the absorbing aerosol is then calculated from the attenuation and is reported as an equivalent black carbon (eBC). Since this is only a consistency test, the Aethalometer data, which is available for Mukteshwar only (Hyvärinen et al., 2009), is used without typical corrections (e.g. Weingartner et al. 2003), which means that the absolute $\mathrm{eBC}$ values are uncertain. Even when the absolute $\mathrm{rBC}$ and $\mathrm{eBC}$ values are not directly comparable, Fig.S7 shows that $\mathrm{eBC}$ and $\mathrm{rBC}$ are correlated. Figure $\mathrm{S} 8$ also shows that the $\mathrm{eBC} / \mathrm{rBC}$ ratio is independent of SP2 temperature. This supports the decision that temperature dependent correction is not needed for SP2.

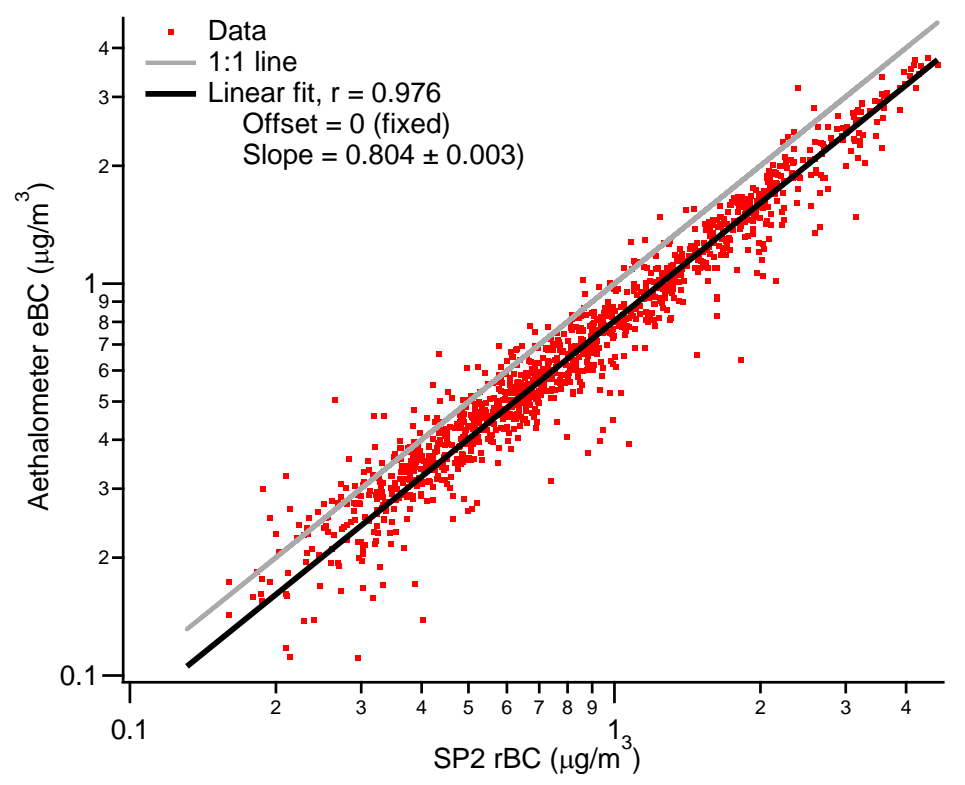

Figure S7: Aethalometer eBC as a function of SP2 rBC and linear fit to data (clear outliers not shown). 


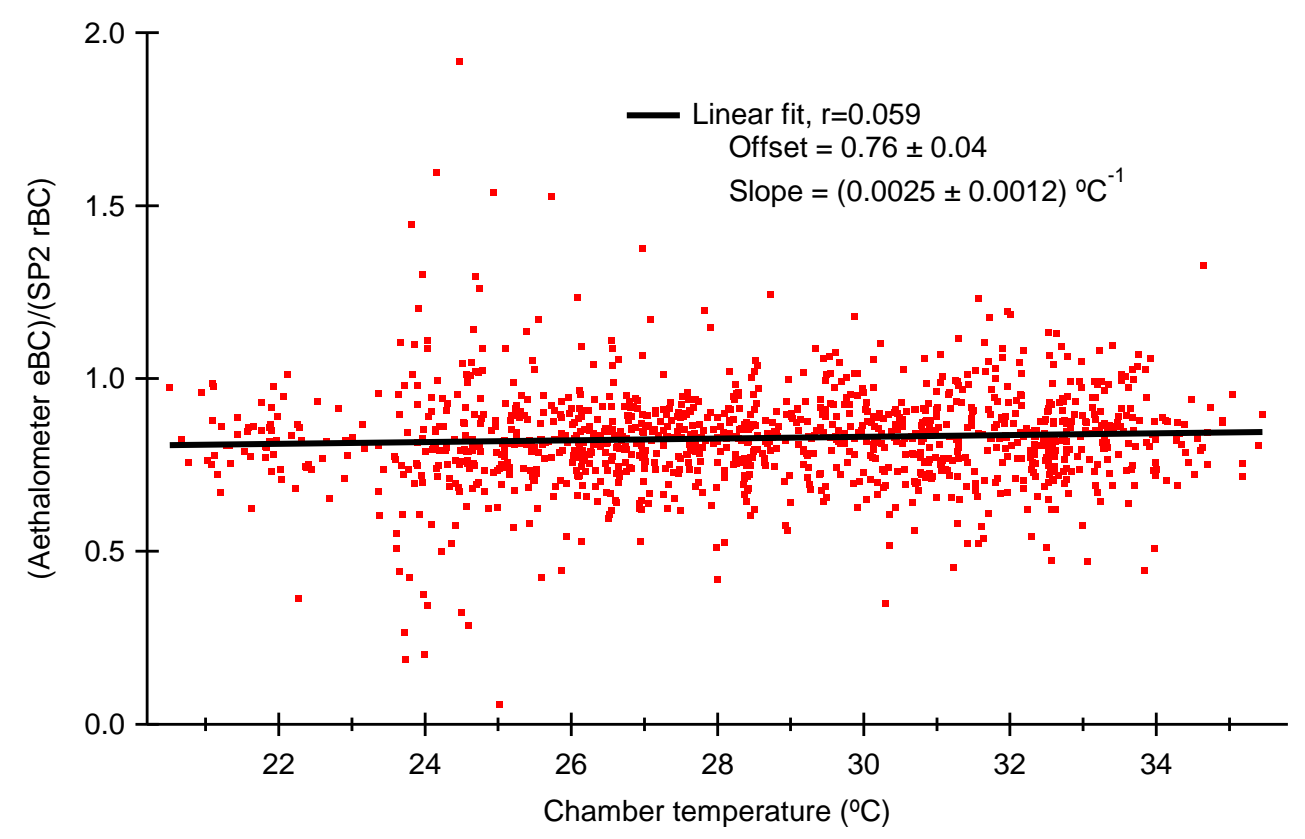

Figure S8: The ratio of Aethalometer eBC to SP2 rBC as a function of SP2 chamber temperature (outliers not shown). Also shown is a linear fit to the data.

\subsection{Laser power diagnostics}

Figure S9 shows the development of the low gain scattering signal amplitudes for the $285 \mathrm{~nm}$ DMA size during the whole measurement period (blue and red marker colors represent Mukteshwar and Gual Pahari, respectively). Also shown is the chamber temperature, which can explain most fluctuations in scattering amplitudes (and particle sizes as shown above). The normalization is based on scattering calibration made just before sending the instrument to India (13.12.2013). On the average, the scattering signals in Mukteshwar and Gual Pahari are reduced to $93 \%$ and $41 \%$ from the calibration level. The reason for the decrease in the scattering signal when the instrument was transported from Mukteshwar to Gual Pahari is unknown, but it is possible that laser power has decreased.

Too low laser power could mean that rBC in the smallest and/or thickly coated particles is not detected. This is examined by calculating the positions for the maximum incandescence signal. The maximum incandescence signal should be seen before particles cross the laser beam center. Figure S10 shows the distributions of times from incandescence signal to the laser beam center for different mobility diameters and $\mathrm{rBC}$ core diameters (half of the mobility diameter $\pm 5 \mathrm{~nm}$ ). Variable core sizes were selected so that these would be representative of the typical particles. The data has been selected from one day with low scattering signal amplitudes. Figure S10 shows that laser power is high enough for particles with mobility diameter at least $220 \mathrm{~nm}$ (rBC core diameter $110 \mathrm{~nm}$ ). Smaller mobility diameters and rBC cores may have reduced detection efficiency especially in Gual Pahari. The $200 \mathrm{~nm}$ mobility size limit used in the main text is therefore suitable for $\mathrm{rBC}$. 


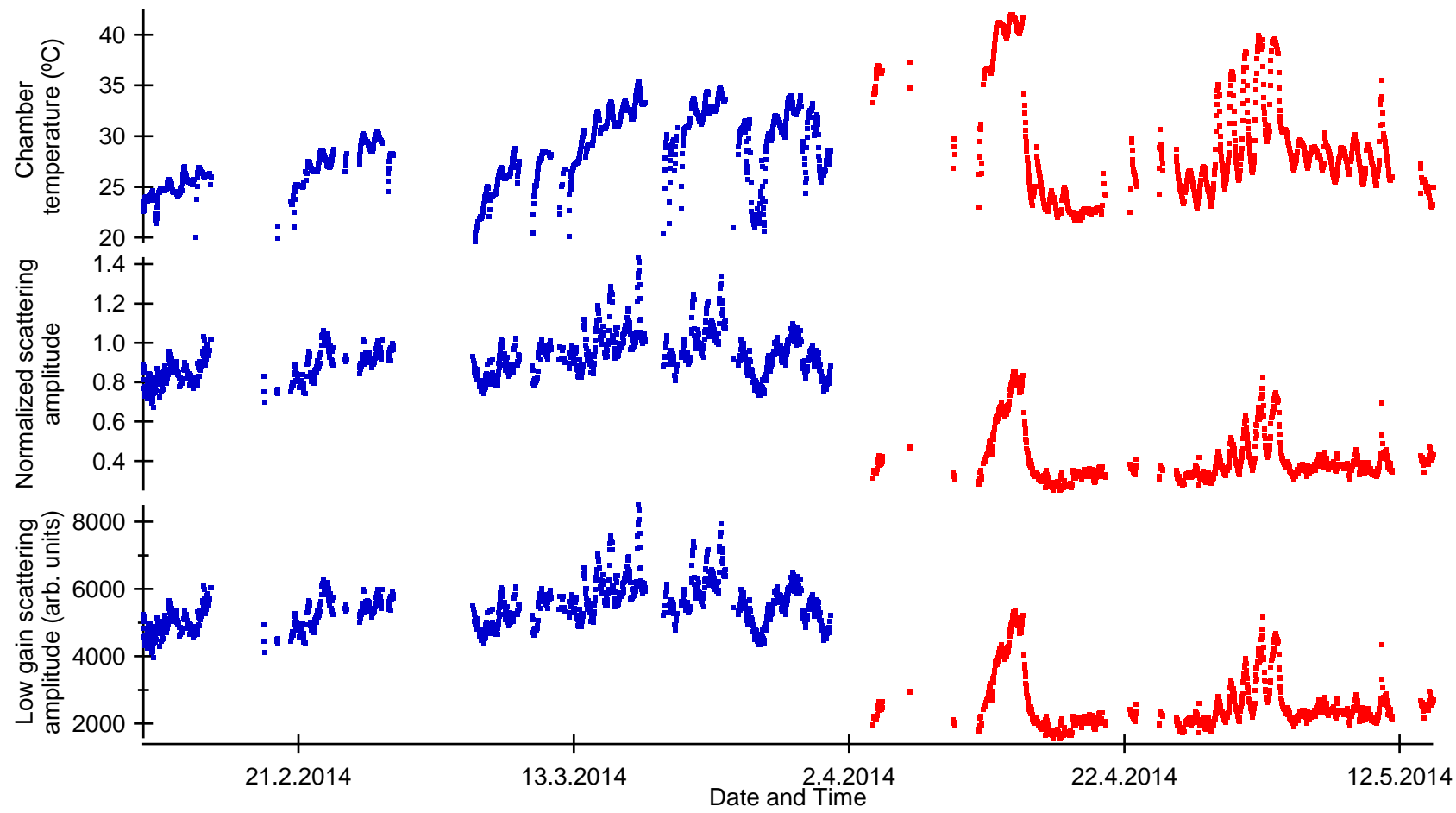

Figure S9: SP2 chamber temperature and measured and normalized scattering amplitudes for Mukteshwar

(blue markers) and Gual Pahari (red markers). Scattering amplitudes are for the $285 \mathrm{~nm}$ DMA size. The normalization is based on scattering calibration made before sending the instrument to India (13.12.2013).
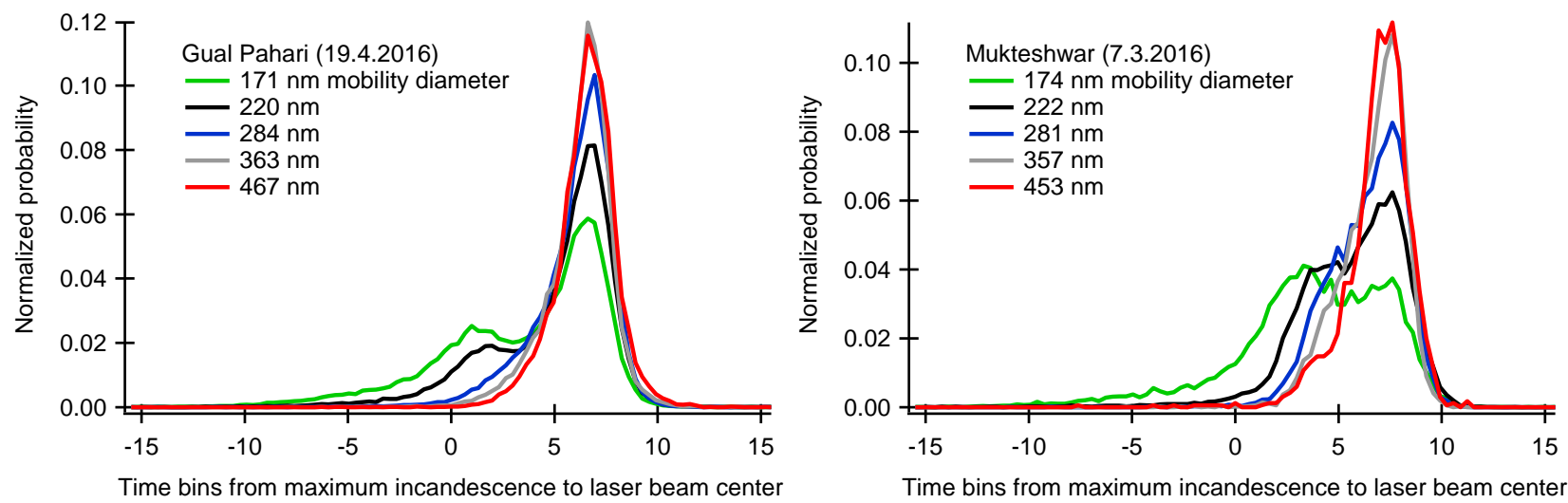

Figure S10: Normalized distributions of incandescence to laser beam center time bins for Gual Pahari and Mukteshwar. The distributions are shown for different mobility and $\mathrm{rBC}$ core diameters (core diameter is half of the mobility diameter).

Significant problems with laser could also affect scattering peak height distributions, but such problems were not seen. As an example, scattering peak height distribution for the $285 \mathrm{~nm}$ mobility size bin is shown in Fig. S11 for both Gual Pahari (top) and Mukteshwar (bottom). The maximum peak height for the current instrument is about 65000 (depends on the baseline noise) and the peak close to this limit corresponds to saturated signal. As is already shown in Fig. S9, scattering amplitudes are somewhat lower in Gual Pahari. 

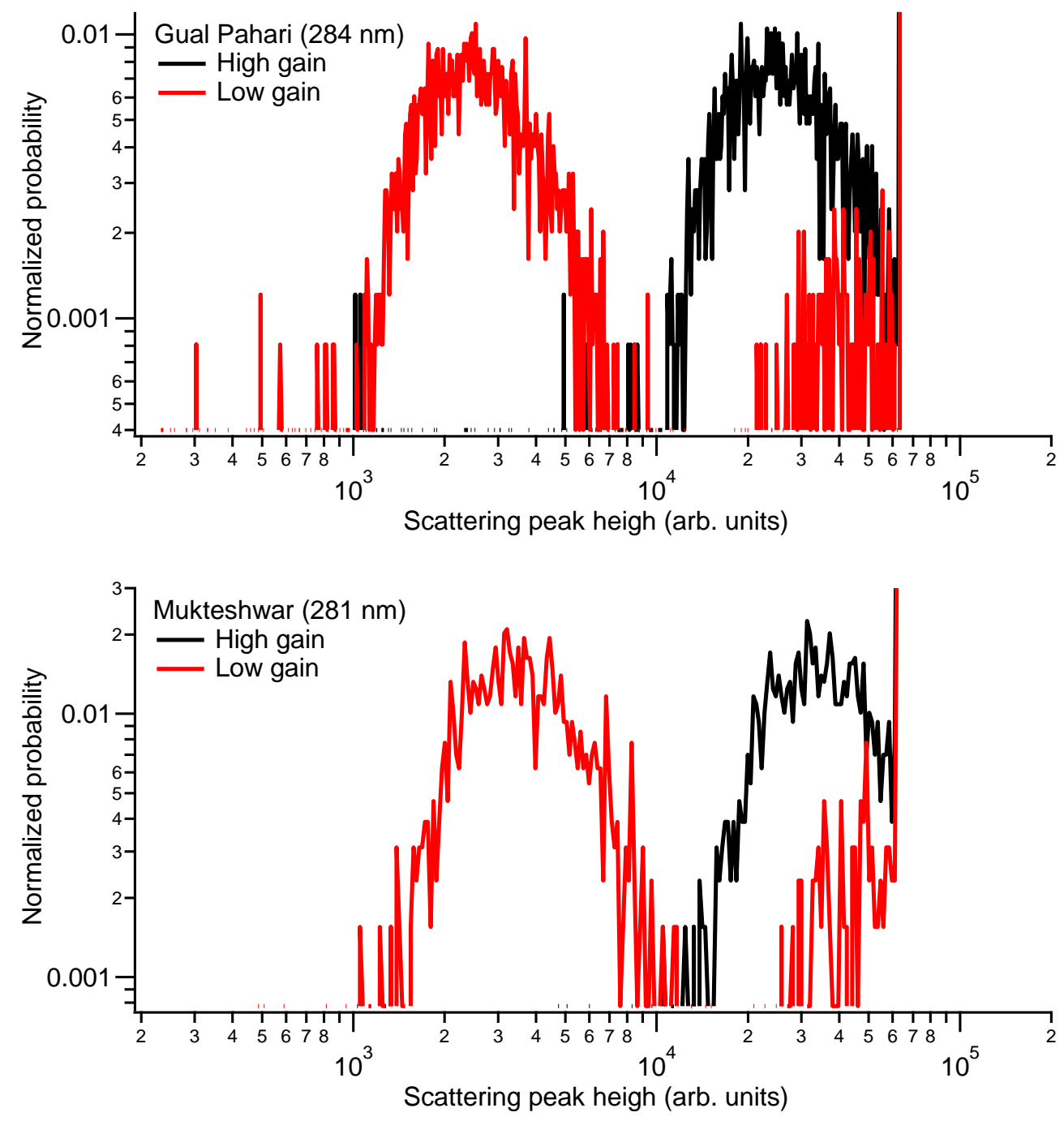

Figure S11: Scattering peak height distributions for $280 \mathrm{~nm}$ mobility size for Gual Pahari (top) and Mukteshwar (bottom).

\section{Supplementary figures}

In addition to the average rBC mass size distributions (total mass and geometric mass mean diameter and standard deviation) and mixing state (number and volume mean core diameters, those normalized by the mobility size, and number fraction of particles containing $\mathrm{rBC}$ ) parameters for the $360 \mathrm{~nm}$ mobility size bins given in the main text (Table 1), figures S12 and S13 show the time series of these parameters (except number and volume mean core diameters as these are proportional to the normalized values). 


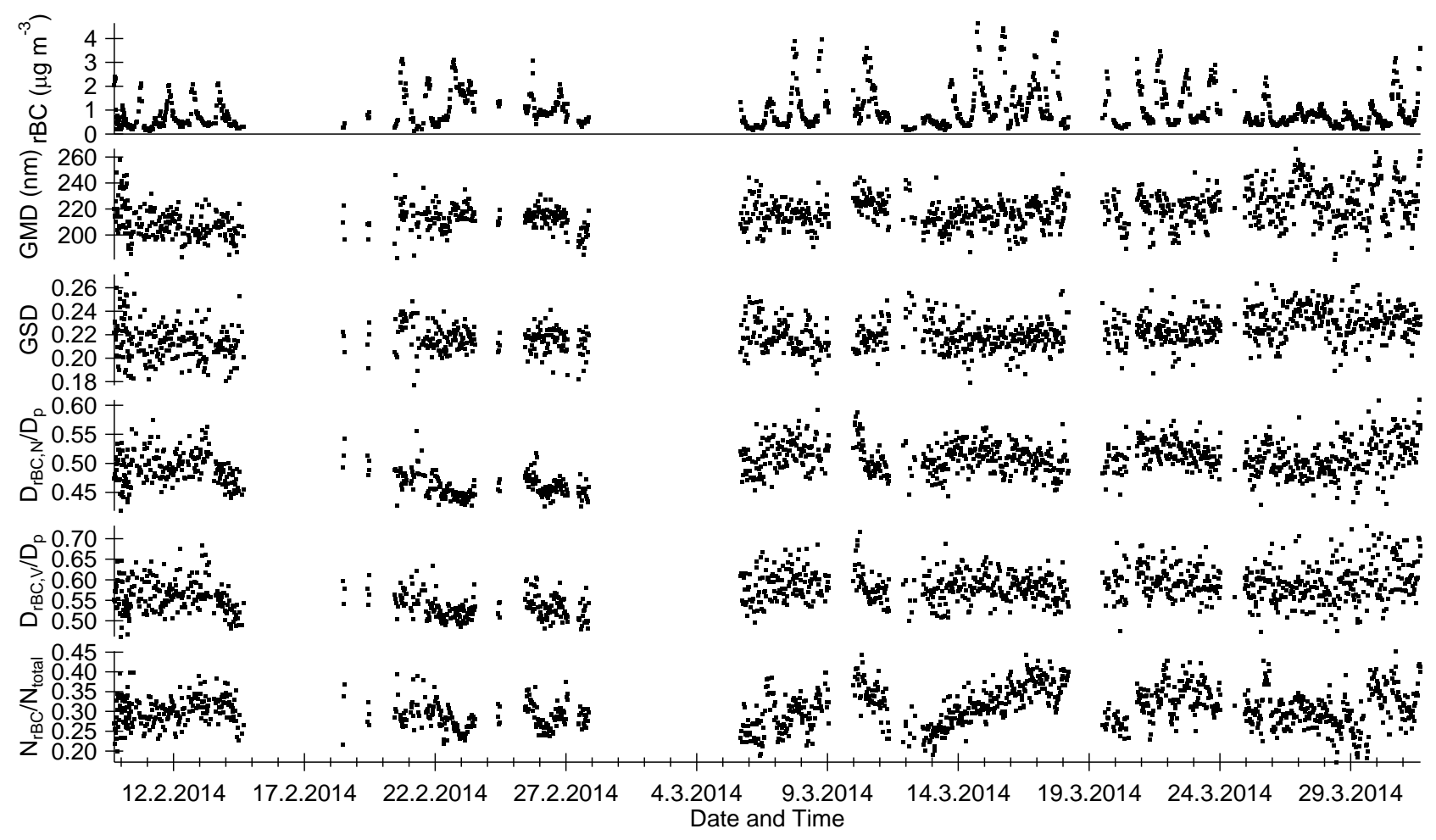

Figure S12: Time series of the measured $\mathrm{rBC}$ mass size distribution parameters (total $\mathrm{rBC}$ concentration and geometric mass mean diameter and standard deviation) and mixing state parameters ( $\mathrm{rBC}$ core volume equivalent diameter (both number and volume averages) to mobility diameter ratio and number fraction of particles containing rBC) for Mukteshwar.

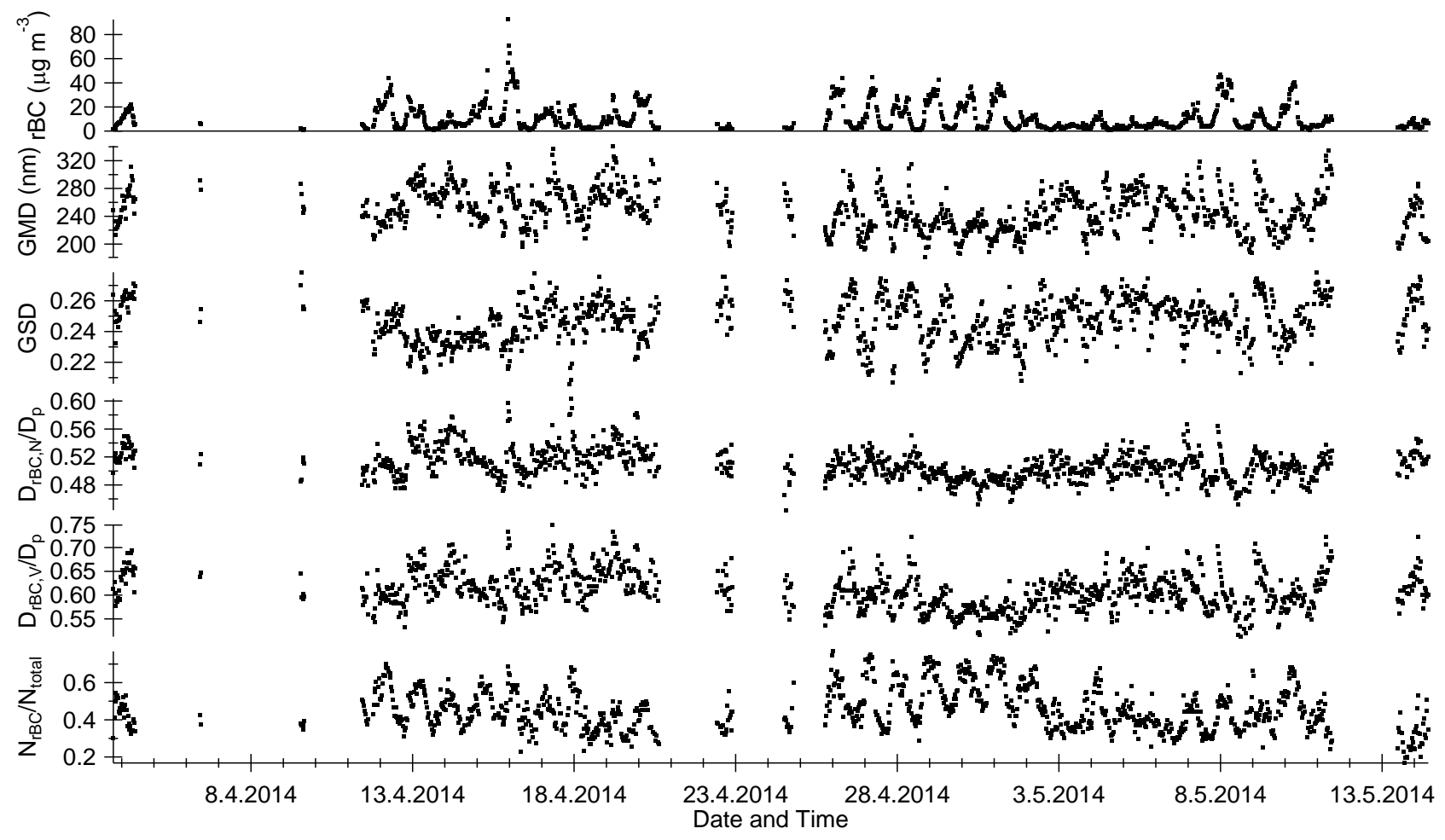

Figure S13: Same as Fig. S12, but for Gual Pahari 
Figure 3 in the main text shows the campaign average rBC core number size distributions for the $360 \mathrm{~nm}$ DMA-selected mobility diameter. Here Fig. S14 shows the core number size distributions for $220 \mathrm{~nm}, 360$ $\mathrm{nm}$ and $520 \mathrm{~nm}$ mobility diameters and also with one standard deviation error bars. The $360 \mathrm{~nm}$ figure is the same as in the main text, but now with the error bars, and the other two sizes represent the lower and upper limits for accurate measurements. As mentioned in the main text, the mode with smaller rBC cores observed in Mukteshwar is below the detection limit $(70 \mathrm{~nm})$ for the measurements with $220 \mathrm{~nm}$ mobility diameter. The error bars represent the variability of the $\mathrm{rBC}$ mass concentrations.
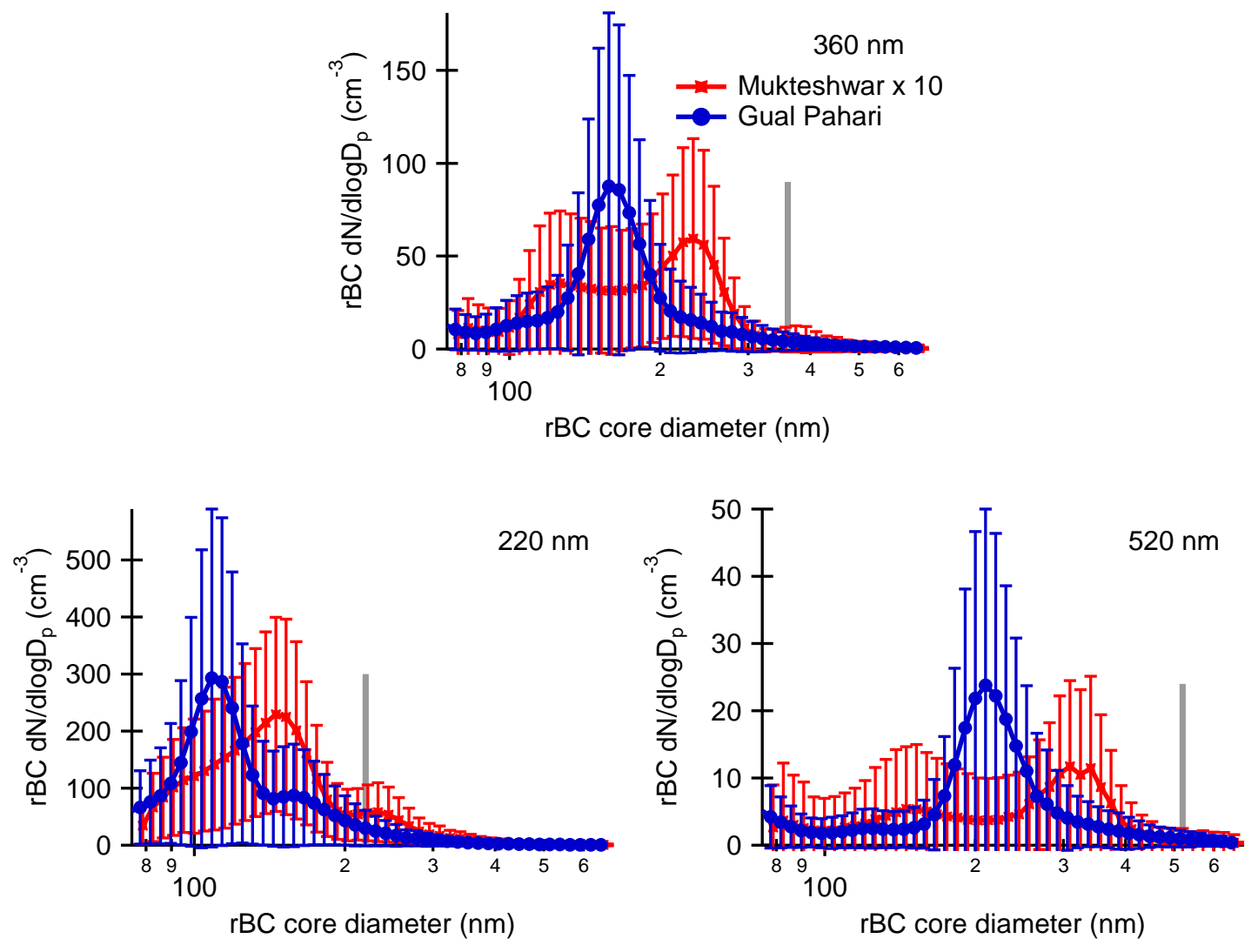

Figure S14: Campaign average rBC core number size distributions for 220, 360 and $520 \mathrm{~nm}$ DMA-selected mobility diameters (indicated by the vertical gray lines) from Mukteshwar (multiplied by a factor of ten) and Gual Pahari.

Refractory black carbon size mass and number distributions as a function of $\mathrm{rBC}$ core volume equivalent diameter are shown in the main text (Fig. 4). Figure S15 shows $\mathrm{rBC}$ and total particle number and mass size distributions measured by the SP2 and DMPS as a function of the DMA-selected mobility diameter. 

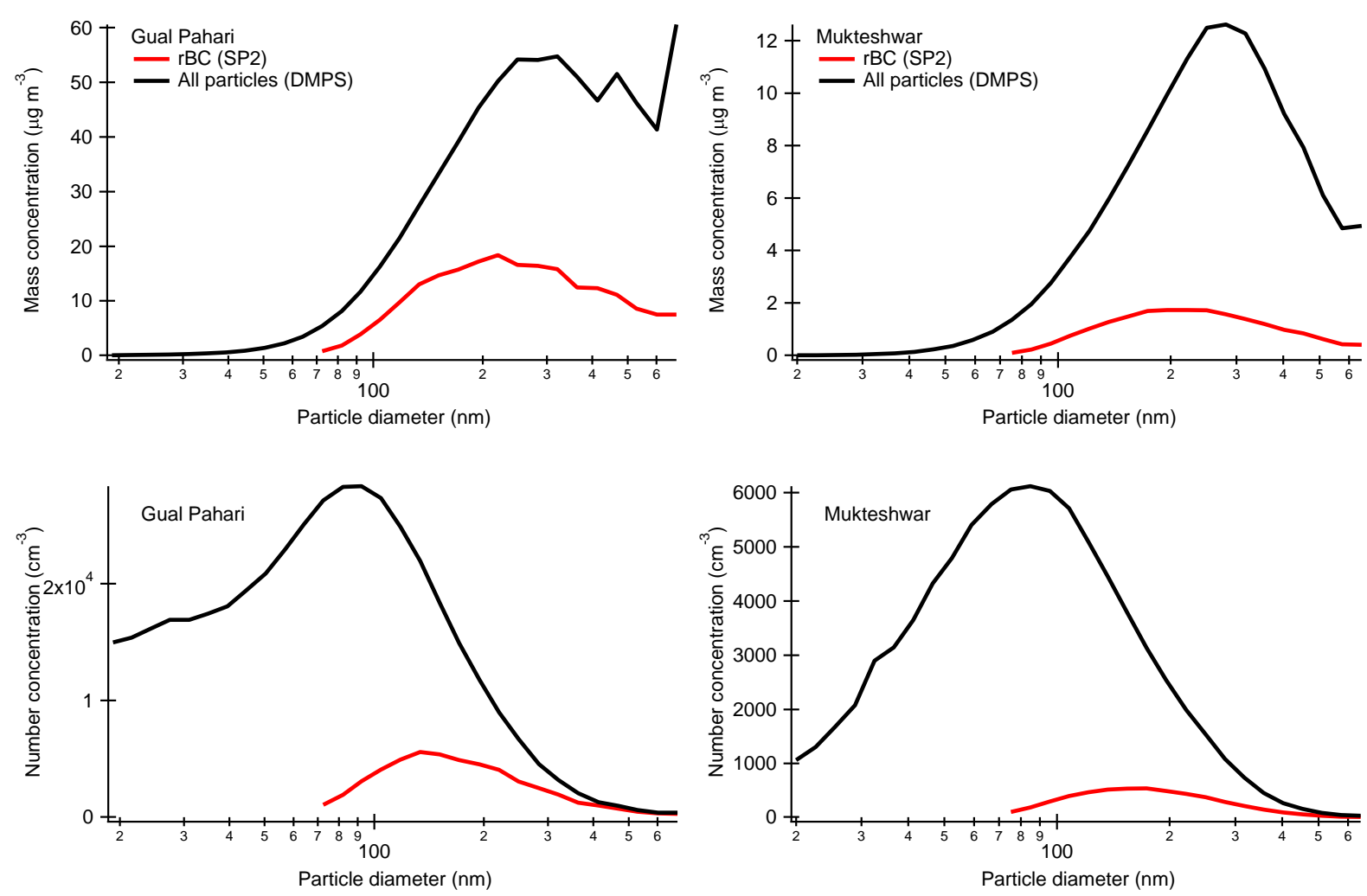

Figure S15: Total and rBC mass and number size distributions measured by the DMPS and SP2 for Gual Pahari and Mukteshwar. The volume distributions measured by the DMPS have been converted to mass by using $1000 \mathrm{~kg} \mathrm{~m}^{-3}$ particle density.

LEO analysis was conducted as described in the main text. Time series of the particles sizes (number average for each hour and mobility size bin) were calculated for different particle types (with and without $\mathrm{rBC}$ ). Although the LEO method seems to work well for particles without $r B C$, examination of the chamber temperature dependency reveals problems with rBC-containing particles. Figure S16 shows the dependency of the LEO-derived optical particle size on the SP2 chamber temperature for particles without (top) and with rBC (bottom) for the $360 \mathrm{~nm}$ mobility size bin. When the size for non-rBC particles is independent if the instrument temperature, this is not the case for rBC-containing particles. The exact reason for this dependency is unknown, but an unusual sinusoidal noise signal seen on top of the Gaussian scattering signal seem to disturb the LEO fit especially at chamber temperature below $30{ }^{\circ} \mathrm{C}$. For this reason, LEO results are presented briefly in the main text (only averages for the $360 \mathrm{~nm}$ mobility size and when chamber temperature is at least $30^{\circ} \mathrm{C}$ ). 

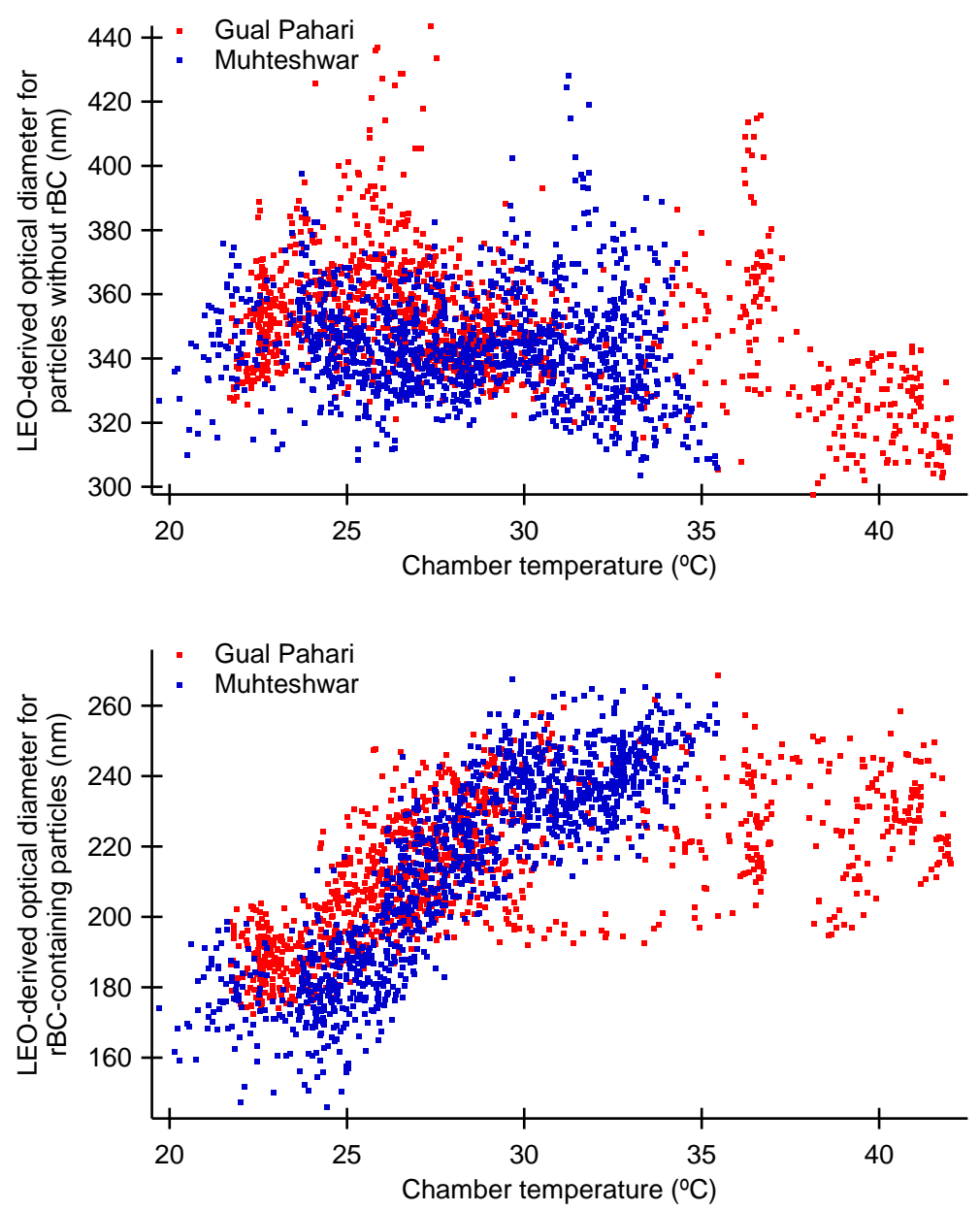

Figure S16: LEO-derived optical particle sizes as a function of chamber temperature for the $360 \mathrm{~nm}$ mobility size bin. The top graph is for particles without $\mathrm{rBC}$ and the bottom graph is for $\mathrm{rBC}$-containing particles.

Clear outliers are not shown.

\section{References}

Baumgardner, D., Popovicheva, O., Allan, J., Bernardoni, V., Cao, J., Cavalli, F., Cozic, J., Diapouli, E., Eleftheriadis, K., Genberg, P. J., Gonzalez, C., Gysel, M., John, A., Kirchstetter, T. W., Kuhlbusch, T. A. J., Laborde, M., Lack, D., Müller, T., Niessner, R., Petzold, A., Piazzalunga, A., Putaud, J. P., Schwarz, J., Sheridan, P., Subramanian, R., Swietlicki, E., Valli, G., Vecchi, R., and Viana, M.: Soot reference materials for instrument calibration and intercomparisons: a workshop summary with recommendations, Atmos. Meas. Tech., 5, 1869-1887, 2012.

Gysel, M., Laborde, M., Olfert, J. S., Subramanian, R., and Gröhn, A. J.: Effective density of Aquadag and fullerene soot black carbon reference materials used for SP2 calibration, Atmos. Meas. Tech., 4, 2851-2858, 2011.

Hansen, A., Rosen, H., and Novakov, T.: The aethalometer - An instrument for the real-time measurement of optical absorption by aerosol particles, Sci. Total Environ., 36, 191-196, 1984. 
Hyvärinen, A.-P., Lihavainen, H., Komppula, M., Sharma, V. P., Kerminen, V.-M., Panwar, T. S., and Viisanen, Y.: Continuous measurements of optical properties of atmospheric aerosols in Mukteshwar, northern India, J. Geophys. Res., 114, D08207, 2009.

Kondo, Y., Sahu L., Moteki, N., Khan, F., Takegawa, N., Liu, X., Koike, M., and Miyakawa T.: Consistency and Traceability of Black Carbon Measurements Made by Laser-Induced Incandescence, Thermal-Optical Transmittance, and Filter-Based Photo-Absorption Techniques, Aerosol Sci. Technol., 45, 295-312, 2011.

Laborde, M., Schnaiter, M., Linke, C., Saathoff, H., Naumann, K.-H., Möhler, O., Berlenz, S., Wagner, U., Taylor, J. W., Liu, D., Flynn, M., Allan, J. D., Coe, H., Heimerl, K., Dahlkötter, F., Weinzierl, B., Wollny, A. G., Zanatta, M., Cozic, J., Laj, P., Hitzenberger, R., Schwarz, J. P., and Gysel, M.: Single Particle Soot Photometer intercomparison at the AIDA chamber, Atmos. Meas. Tech., 5, 3077-3097, doi:10.5194/amt-5-3077-2012, 2012.

Moteki, N., and and Kondo, Y.: Dependence of Laser-Induced Incandescence on Physical Properties of Black Carbon Aerosols: Measurements and Theoretical Interpretation, Aerosol Sci. Technol., 44, 663-675, 2010.

Weingartner, E., Saathoff, H., Schnaiter, M., Streit, N., Bitnar, B., and Baltensperger, U.: Absorption of light by soot particles: determination of the absorption coefficient by means of aethalometers, J. Aerosol Sci., 34, 1445-1463, 2003.

Wiedensohler, A., Birmili, W., Nowak, A., Sonntag, A., Weinhold, K., Merkel, M., Wehner, B., Tuch, T., Pfeifer, S., Fiebig, M., Fjäraa, A. M., Asmi, E., Sellegri, K., Depuy, R., Venzac, H., Villani, P., Laj, P., Aalto, P., Ogren, J. A., Swietlicki, E., Williams, P., Roldin, P., Quincey, P., Hüglin, C., Fierz-Schmidhauser, R., Gysel, M., Weingartner, E., Riccobono, F., Santos, S., Grüning, C., Faloon, K., Beddows, D., Harrison, R., Monahan, C., Jennings, S. G., O'Dowd, C. D., Marinoni, A., Horn, H.-G., Keck, L., Jiang, J., Scheckman, J., McMurry, P. H., Deng, Z., Zhao, C. S., Moerman, M., Henzing, B., de Leeuw, G., Löschau, G., and Bastian, S.: Mobility particle size spectrometers: harmonization of technical standards and data structure to facilitate high quality longterm observations of atmospheric particle number size distributions, Atmos. Meas. Tech., 5, 657-685, doi:10.5194/amt-5-657-2012, 2012. 